\title{
Anastomotic loop between common hepatic artery and gastroduodenal artery in coexistence with an aberrant right hepatic artery
}

\author{
K. Natsis ${ }^{1}$, M. Piagkou², T. Stamatopoulos ${ }^{3}$, I. Spyridakis ${ }^{3}$, S. Apostolidis ${ }^{1}$ \\ ${ }^{1}$ Department of Anatomy, School of Medicine, Faculty of Health Sciences, Aristotle University of Thessaloniki, Greece \\ ${ }^{2}$ Department of Anatomy, School of Medicine, Faculty of Health Sciences, National and Kapodistrian University \\ of Athens, Greece \\ ${ }^{3} 2^{\text {nd }}$ Department of Paediatric Surgery, Papageorgiou Hospital, School of Medicine, Aristotle University of Thessaloniki, Greece
}

[Received: 20 December 2016; Accepted: 20 February 2017]

\begin{abstract}
Anatomical variations of the hepatic arteries are not uncommon. The anomalous hepatic arterial supply is of paramount importance in hepatobiliary, pancreatic or liver transplantation and in laparoscopic surgery. We describe an unusual case of a 66-year-old Greek male cadaver, where a rare anastomosis (in the form of an enlarged arterial loop, $4.84 \mathrm{~mm}$ in diameter) between the common hepatic artery $(6.42 \mathrm{~mm})$ and the gastroduodenal artery (GDA) $(4.82 \mathrm{~mm})$ coexisted with an aberrant right hepatic artery (ARHA) $(6.38 \mathrm{~mm})$ originating from the superior mesenteric artery. The proper hepatic artery was absent. The ARHA followed a route posterior to the portal vein and the common hepatic duct, entering the liver and supplying the right hepatic segment. A hypoplastic right gastric artery emanated from the GDA. Our case report highlights the combined variations of hepatic arteries and possible anastomoses emphasizing that a thorough knowledge of the classic and variable hepatic arterial anatomy are mandatory for surgeons and radiologists performing hepatic surgery and arteriography to avoid potential iatrogenic injuries in hepatobiliary and pancreas area and further medico-legal implications. (Folia Morphol 2017; 76, 4: 752-756)
\end{abstract}

Key words: coeliac trunk, hepatic artery, common hepatic artery, right hepatic artery, left hepatic artery, gastroduodenal artery, right gastric artery, variation, anastomosis

\section{INTRODUCTION}

Arterial vascularisation of the gastrointestinal tract is provided by the anterior branches of the abdominal aorta, i.e. the coeliac trunk (CT), the superior mesenteric artery (SMA) and the inferior mesenteric artery (IMA). The typical CT division in 3 branches (the socalled hepatogastrosplenic trunk) is constituted by the left gastric artery (LGA), the splenic artery (SA) and the common hepatic artery (CHA) (type I according to Michel's classification) occurring in 55-89\% of the dissections and arteriograms performed over the last 50 years $[4,10,17,29]$. Differences arising during several developmental stages in embryos lead to a range of variations in CT branching pattern [25]. The

Address for correspondence: Assistant Prof. M. Piagkou, Department of Anatomy, School of Medicine, Faculty of Health Sciences, National and Kapodistrian University of Athens, M. Asias 75 Street, 11527, Athens, Greece, tel: +30 2107462427, fax: +30 2107462398, e-mail: mapian@med.uoa.gr 
$\mathrm{CT}$ and hepatic arteries (HAs) anatomical variability is of paramount importance in patients undergoing hepatobiliary, pancreatic or liver transplantation [2] and in laparoscopic surgery, since bleeding from aberrant vessels may increase the risk of intraoperative complications [11]. The surgeon should always identify the presence of an anomalous HA before proceeding with pancreas resection [12]. Moreover, in radiological abdominal interventions and penetrating abdominal injuries the frequency of HAs iatrogenic injury increases in cases of variant anatomy (presence of ectopic and anastomotic branches). In clinical practice, unless the provided ischaemia when symptomatic, the HAs variability is usually a random intraoperative or interventional finding [11].

The current brief communication aims to highlight a rare case of an anastomotic loop between the CHA and the gastroduodenal artery (GDA) in coexistence with an aberrant right hepatic artery (ARHA).

\section{CASE REPORT}

During educational dissection of the abdomen of a 66-year-old Greek male cadaver in anatomy lab, a rare anastomosis (in the form of an enlarged arterial loop) between the CHA (6.42 $\mathrm{mm}$ in diameter) and the GDA coexisted with an ARHA originating from the SMA. The CT gave off the CHA, the LGA and the SA. The LGA travelled superiorly supplying the distal oesophagus and then descended along the lesser curvature of the stomach. The SA located on the posterior surface of the body and tail of the pancreas supplying the spleen after giving off several pancreatic branches. The CHA coursed horizontally along the upper border of the head of the pancreas and then turned upwards to ascend in the lesser omentum. The CHA ended at the level of the GDA origin $(7.98 \mathrm{~mm}$ in diameter) after which it continues as the left hepatic artery (LHA) $(5.70 \mathrm{~mm}$ ) to the porta hepatis, while no proper hepatic artery and right hepatic artery (RHA) existed. A thick anastomotic branch $(4.84 \mathrm{~mm}$ in diameter and $19.25 \mathrm{~mm}$ in length) was observed between CHA and GDA. The large loop anastomosis had a similar diameter with the GDA before the anastomosis $(4.82 \mathrm{~mm})$, while after the anastomosis the GDA had a diameter of $6.63 \mathrm{~mm}$. After the meticulous dissection of the portal triad and the lesser omentum, an ARHA (6.38 $\mathrm{mm}$ in diameter) was identified, originating from the SMA. The ARHA did not give off any branch to the adjacent organs; it followed a route posterior to the portal vein and the common

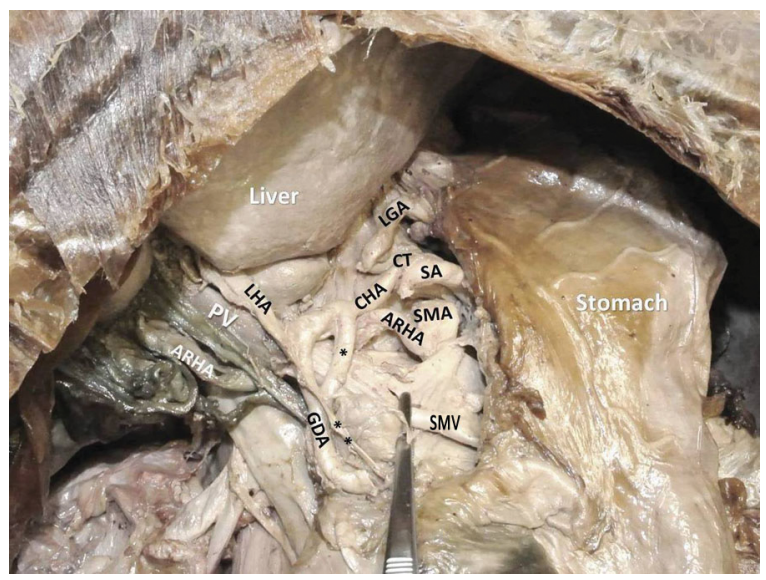

Figure 1. The coeliac trunk (CT) branching pattern (left gastric artery [LGA], splenic artery [SA] and common hepatic artery [CHA]). Left hepatic artery (LHA) and gastroduodenal artery (GDA) originated from the CHA. The aberrant right hepatic artery (ARHA) takes origin from the superior mesenteric artery (SMA) and courses posterior to the portal vein (PV); * anastomotic loop between CHA and $\mathrm{GDA} ;{ }^{* *}$ the right gastric artery (RGA). The forceps indicates the superior mesenteric vein (SMV).

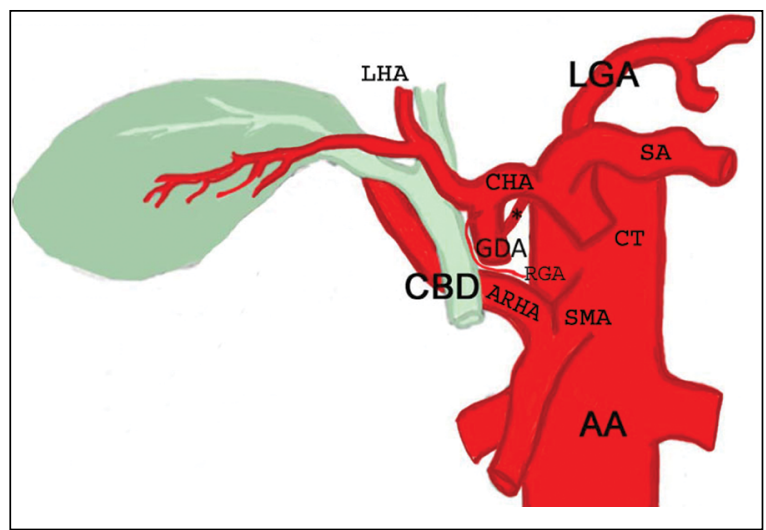

Figure 2. Schematic representation of the coeliac trunk (CT) division into the left gastric artery (LGA), splenic artery (SA) and common hepatic artery (CHA). Left hepatic artery (LHA) and gastroduodenal artery (GDA) originated from the CHA. The aberrant right hepatic artery (ARHA) takes origin from the superior mesenteric artery (SMA) and courses posterior to the common bile duct (CBD); AA - aorta; *anastomotic branch between CHA and GDA and the right gastric artery (RGA).

bile duct, entering the liver and supplying the right hepatic segment. The right gastric artery (RGA) was hypoplastic and originated from the GDA (Figs. 1, 2). The GDA coursed inferiorly between duodenum and pancreas, terminating into the right gastroepiploic and the superior (anterior and posterior) pancreaticoduodenal arteries. 


\section{DISCUSSION}

The hepatic arterial supply is derived from the CT in $55 \%$ of the subjects [16]. In a variable incidence ranging from $4.5 \%$ [10] to $45 \%$ [24], the $\mathrm{CHA}$, the RHA or LHA may arise from other vessels than the $\mathrm{CT}$ and are characterised as aberrant HAs (AHAs). Recognition of the atypical HAs and understanding of the embryologic background of the liver would help surgeons to avoid serious complications (like hepatic infarction after ligation of an AHA) when perform hepatic resection [2], pancreatoduodenectomy and lymphadenectomy around $\mathrm{CT}$ and mesenteric arteries $[11,12]$. An AHA may also pose technical difficulties for infusion therapy and transarterial chemoembolisation of neoplasms [14]. The incidence of CT and HAs variations increases with the presence of accessory renal arteries [28].

Tandler [25] explained the CT and SMA morphogenesis hypothesizing that four primitive splanchnic arteries originate from the dorsal aorta in foetuses and these arteries are connected to the ventral longitudinal anastomoses. During development, the primitive arteries are converged into the CT, SMA and IMA and the longitudinal anastomoses (between CT-SMA and SMA-IMA) disappear. The hepatic arterial supply in early gestation life derives from the LHA (LGA origin), from the CHA from (CT origin) and the RHA (SMA origin) [3]. With further development, blood supply assumes the adult pattern (in $67 \%$ of the individuals) [18] and after the atrophy of both right and left HAs, the CHA becomes the unique supply of the liver. The persistence and/or abnormal regression of parts of this primitive arterial system account for numerous CT and HAs alterations. A handicap of the great variability of HAs is the increase of vascular lesions development in hepatobiliary and pancreatic area. Few years earlier, the presence of AHAs could be a contraindication for surgery [10]. Nowadays, the AHAs can be easily manipulated and oncologic surgery of the pancreatic head is feasible in the presence of variant HAs [12]. Concerning surgery planning, variant HAs are technically demanding, as they lead to a more conservative pancreas resection, leading to an inadequate tumour removal [31]. By contrast, a more aggressive surgery based on preservation of the anomalous HAs may increase the operating time, the risk for greater blood loss and the postoperative morbidity. Thus, intervening surgeon must evaluate advantages and disadvantages of each technique and take the final decision after having thoroughly studied the detailed HAs anatomy, i.e. location, branching pattern and possible anastomoses. Moreover, the HAs identification will help to avoid serious ischaemic complications in liver transplantations.

In the majority of individuals (86\%) [30], as in our case, the CHA takes origin from the $\mathrm{CT}$. The commonest variant is the CHA absence (12\%) [29]. Alternatively, the CHA may arise from the SMA $(2-4.5 \%)[5,18$, $26]$, the aorta $(1.1 \%)$, the LGA $(0.54 \%)$, or even rarer sources [30]. Accidental ligation of the $\mathrm{CHA}$ will result in hepatic ischaemia and necrosis and will jeopardize the duodenum. With the increasing use of multidetector computed tomography scan in combination with selective angiography before pancreatic surgery, the accurate knowledge of the HAs and computed tomography anatomy assumes significance. Moreover, the demonstration of the three-dimensional (3D) features of these vessels in relation to the adjacent organs is of unique significance.

The typical RHA may arise from the proper hepatic artery in an incidence ranging from $65 \%$ [1] to $86.6 \%$ [19] or from the CHA in 20\% [1]. Other variations occur in 6-18\%, as either an ARHA from the SMA (6-11\%) [4-6, 10, 17, 29] or as an accessory RHA ( $2^{\text {nd }}$ RHA presence) $(2-8 \%)[4,6,10]$. In case of CHA absence, the ARHA or accessory RHA may originate from the SMA $(3.5-17 \%)[1,9,24]$ or the aorta. In our case, no proper HA existed and the ARHA originated from the SMA. Michels [16] reported an ARHA originated from the SMA in $12.5 \%$, the CT in $3 \%$, the aorta in $2 \%$ and the LGA in $0.5 \%$. Perez-Saborido et al. [21] mentioned the highest incidence of 38.2-38.7\% for an ARHA with a SMA origin among liver donors and recipients in a total 325 liver transplantations. The atypical RHA may have an unpredictable course, but it is always related to the head and neck of the pancreas. There have been reports of such vessels coursing behind or through the pancreatic head, in which the ARHAs are susceptible to damage. In our case, the ARHA coursed lateral and behind the portal vein and entered the hepatoduodenal ligament posterolateral to the common hepatic duct, as mentioned by Michels [18] and Woodburne and Russel [33]. The ARHA injury affects the liver and specifically the bile duct vascularity with the attendant risk of a leak in the bilioenteric anastomosis [27]. The ARHA may have unusual relations in the right free border of the lesser omentum and present hazards while performing cholecystectomy [19]. An ARHA originated from the SMA has high chances of being encompassed 
by cephalo-pancreatic tumours [12]. During surgery, the presence of such types of the ARHAs may involve longer operative time and consequently increase the postoperative morbidity and mortality due to the vessels injury. From the clinical point of view, an ARHA originated from the SMA may not cause problems, unless the SMA is compromised due to occlusion. Thus liver may become necrotic along with the gut. Preoperative detection of the ARHAs is essential in liver transplantations. Several authors [20, 22, 32] suggested that an ARHA is a beneficial variant in the right liver living donors. The common postoperative complication in liver transplantation is HA thrombosis due to the shorter and thinner HA graft. But the ARHA in right lobe liver donor provides a longer and a larger graft, so the chance of HA thrombosis is less in them [15]. The ARHA in liver transplant recipient increases risk of HA complications after transplantation due to the small calibre of the CHA [11].

The LHA usually originates from the proper HA in $71.6 \%[1,8]$ or from the $\mathrm{CHA}$ in $16 \%[1,23]$, as in our case. In $25-30 \%$, the LHA originated from the LGA [18, 30], as an aberrant LHA [7]. In cases where the LHA arises from the right side of the SMA or the GDA, it presents a problem in pancreatic surgery. The LHA may also emanate from the SA in 1.7\% [1] or from the aorta, or from the $\mathrm{CT}$ in $10 \%$ [1] in cases of CHA absence [7, 13].

The normal GDA originated from the CHA in 75\% of the specimens $[5,16]$, as in our case. Variations in its origin are commonly due to the CHA variants. As such, it may also arise from an aberrant CHA (off the SMA), from an ARHA, or the LHA [29] or the CT in $0.3 \%$ of the cases [4].

The RGA may originate from the CHA or the proper HA or the LHA in $40 \%$ of the cases [5] and collateralises along the lesser curvature with the LGA. More rarely the RGA may originate from the RHA ( $11 \%)$ of from the GDA (8\%) [16], as in the current case.

\section{CONCLUSIONS}

An ARHA originating from the SMA coexisted with an anastomotic loop between the $\mathrm{CHA}$ and the GDA arising as the last branch of the CHA. No proper and right hepatic artery existed. The RHA is subject to anatomical variations in its origin and course. Our case report highlights these variations emphasizing that a thorough knowledge of the anatomy of the RHA and its variations in origin and course is mandatory for surgeons and radiolo- gists in performing hepatic surgery and hepatic arteriography to avoid surgical injuries in the liver during surgical manipulations and further medicolegal implications.

\section{REFERENCES}

1. Bhardwaj N. Anomalous origins of hepatic artery and its significance for hepatobiliary surgery. J Anat Soc India. 2010; 59(2): 173-176, doi: 10.1016/s00032778(10)80020-6.

2. Chaib E, Ribeiro MAF, Saad WA, et al. The main hepatic anatomic variations for the purpose of split-liver transplantation. Transplant Proc. 2005; 37(2): 1063-1066, doi: 10.1016/j.transproceed.2004.11.054, indexed in Pubmed: 15848623.

3. Couinaud C. Surgical anatomy of the liver revisited. C.Couinaud, Paris 1989.

4. Covey AM, Brody LA, Maluccio MA, et al. Variant hepatic arterial anatomy revisited: digital subtraction angiography performed in 600 patients. Radiology. 2002; 224(2): 542-547, doi: 10.1148/radiol.2242011283, indexed in Pubmed: 12147854.

5. Daseler EH, Anson BJ. The cystic artery and constituents of the hepatic pedicle; a study of 500 specimens. Surg Gynecol Obstet. 1947; 85(1): 47-63, indexed in Pubmed: 20249245.

6. De Cecco CN, Ferrari R, Rengo M, et al. Anatomic variations of the hepatic arteries in 250 patients studied with 64-row CT angiography. Eur Radiol. 2009; 19(11): 2765-2770, doi: 10.1007/s00330-009-1458-7, indexed in Pubmed: 19471940.

7. De Martino RR. Normal and Variant Mesenteric Anatomy. Mesenteric Vascular Disease. 2015: 9-23, doi: 10.1007/978-1-4939-1847-82.

8. Gruttadauria S, Foglieni CS, Doria C, et al. The hepatic artery in liver transplantation and surgery: vascular anomalies in 701 cases. Clin Transplant. 2001; 15(5): 359-363, indexed in Pubmed: 11678964.

9. Healey Jr, Schwartz SI. Surgical Anatomy. In: Schwartz SI (ed.) Surgical Diseases of the Liver. McGraw-Hill, New York 1964.

10. Hiatt JR, Gabbay J, Busuttil RW. Surgical anatomy of the hepatic arteries in 1000 cases. Ann Surg. 1994; 220(1): 50-52, indexed in Pubmed: 8024358.

11. Ishigami K, Zhang $Y$, Rayhill $S$, et al. Does variant hepatic artery anatomy in a liver transplant recipient increase the risk of hepatic artery complications after transplantation? AJR Am J Roentgenol. 2004; 183(6): 1577-1584, doi: 10.2214/ajr.183.6.01831577, indexed in Pubmed: 15547194.

12. Jah A, Jamieson N, Huguet $E$, et al. The implications of the presence of an aberrant right hepatic artery in patients undergoing a pancreaticoduodenectomy. Surg Today. 2009; 39(8): 669-674, doi: 10.1007/s00595-009-3947-3, indexed in Pubmed: 19639433.

13. Jones RM, Hardy KJ. The hepatic artery: a reminder of surgical anatomy. J R Coll Surg Edinb. 2001; 46(3): 168-170, indexed in Pubmed: 11478014.

14. Kapoor V, Brancatelli G, Federle MP, et al. Multidetector CT arteriography with volumetric three-dimensional 
rendering to evaluate patients with metastatic colorectal disease for placement of a floxuridine infusion pump. AJR Am J Roentgenol. 2003; 181(2): 455-463, doi: 10.2214/ajr.181.2.1810455, indexed in Pubmed: 12876026.

15. Marcos A, Killackey M, Orloff MS, et al. Hepatic arterial reconstruction in 95 adult right lobe living donor liver transplants: evolution of anastomotic technique. Liver Transpl. 2003; 9(6): 570-574, doi: 10.1053/jlts.2003.50093, indexed in Pubmed: 12783397.

16. Michels NA. Blood supply and anatomy of the upper abdominal organs with a descriptive atlas. Lippincott, Philadelphia, Pa 1955.

17. Michels NA. The anatomic variations of the arterial pancreaticoduodenal arcades: their import in regional resection involving the gall bladder, bile ducts, liver, pancreas and parts of the small and large intestines. J Int Coll Surg. 1962; 37: 13-40, indexed in Pubmed: 14473442.

18. Michels NA. The hepatic, cystic and retroduodenal arteries and their relations to the biliary ducts with samples of the entire celiacal blood supply. Ann Surg. 1951; 133(4): 503-524, indexed in Pubmed: 14819988.

19. Mugunthan N, Jansirani D, Felicia C, et al. Anatomical variations in the arterial supply of liver. Int J Anat Variations. 2012; 5: 107-9.

20. Nakamura T, Tanaka K, Kiuchi T, et al. Anatomical variations and surgical strategies in right lobe living donor liver transplantation: lessons from 120 cases. Transplantation. 2002; 73(12): 1896-1903, indexed in Pubmed: 12131684.

21. Pérez-Saborido B, Pacheco-Sánchez D, Barrera Rebollo A, et al. Incidence of hepatic artery variations in liver transplantation: does it really influence short- and longterm results? Transplant Proc. 2012; 44(9): 2606-2608, doi: 10.1016/j.transproceed.2012.09.064, indexed in Pubmed: 23146470.

22. Peschaud F, El-Hajjam M, Malafosse R, et al. A common hepatic artery passing in front of the portal vein. Surg
Radiol Anat. 2008; 28(2): 202-205, doi:10.1007/s00276005-0063-y, indexed in Pubmed: 16362228.

23. Sultana ZR, Khalil M, Rahman H, et al. Study of anatomical variation of right and left hepatic arteries. Mymensingh Med J. 2009; 18(1 Suppl): S29-S33, indexed in Pubmed: 19377428.

24. Suzuki T, Nakayasu A, Kawabe K, et al. Surgical significance of anatomic variations of the hepatic artery. Am J Surg. 1971; 122(4): 505-512, indexed in Pubmed: 5098656.

25. Tandler JU. Ber die varietaten der arteria coeliaca und derenentwickelung. Anat Hefte. 1904; 25: 475-500.

26. Thompson IM. On the arteries and ducts in the hepatic pedicle; A study in statistical human anatomy. Univ California Publ Anat. 1933; 1: 55.

27. Traverso LW, Freeny PC. Pancreaticoduodenectomy. The importance of preserving hepatic blood flow to prevent biliary fistula. Am Surg. 1989; 55(7): 421-426, indexed in Pubmed: 2742226.

28. Ugurel MS, Battal B, Bozlar U, et al. Anatomical variations of hepatic arterial system, coeliac trunk and renal arteries: an analysis with multidetector $\mathrm{CT}$ angiography. $\mathrm{Br} J$ Radiol. 2010; 83(992): 661-667, doi: 10.1259/bjr/21236482, indexed in Pubmed: 20551256.

29. Valentine RJ, Wind GG. Anatomic exposures in vascular surgery. 2 nd ed. Lippincott Williams \& Wilkins, Philadelphia 2003; xiii: 577

30. Vandamme JP, Bonte J. The branches of the celiac trunk. Acta Anat (Basel). 1985; 122(2): 110-114, indexed in Pubmed: 4013640.

31. Verbeke CS, Leitch $D$, Menon KV, et al. Redefining the R1 resection in pancreatic cancer. Br J Surg. 2006; 93(10): 1232-1237, doi: 10.1002/bjs.5397, indexed in Pubmed: 16804874.

32. Varotti G, Gondolesi GE, Goldman J, et al. Anatomic variations in right liver living donors. J Am Coll Surg. 2004; 198(4): 577-582, doi:10.1016/j.jamcollsurg.2003.11.014, indexed in Pubmed: 15051012.

33. Woodburne, Russell T. Essentials of Human Anatomy, 1st ed. Oxford University Press, New York 1957: 417-422. 